\title{
Improving resilience in intermodal transport operations in seaports: a gaming approach
}

\author{
Shalini Kurapati ${ }^{1} \cdot$ Heide Lukosch $^{1}$ • \\ Alexander Verbraeck ${ }^{1}$ - Frances M. T. Brazier ${ }^{1}$
}

Received: 4 February 2014/ Accepted: 30 June 2015/Published online: 22 July 2015

(C) The Author(s) 2015. This article is published with open access at Springerlink.com

\begin{abstract}
Seaports are crucial interfaces in global intermodal freight transportation networks. Their complex operations, connectedness to external stakeholders, and increasing volumes of goods to be handled make them vulnerable to internal and external disruptions. Research has shown that disruptions in seaports can cause undesirable ripple effects, which negatively impact the operations of the entire transportation network as well as the surrounding economical and societal wellbeing. Containerized transportation plays a major role in the global trade network. Resilience of seaport container terminals is therefore imperative for a resilient and robust intermodal transportation network. Communication, information sharing, alignment of plans, and shared awareness of unfolding disruptions among planners and decision makers within terminal operations have been identified as important elements to improve the resilience of container terminals. However, in practice, the inter-dependencies between various planning and operational activities, and alignment of solution strategies have been largely overlooked. Addressing this gap, a novel approach for creating awareness of potential strategies for disruption management by training competencies for resilient container terminal operations has been introduced in the form of a simulation game. Several test sessions of a multiplayer tabletop game support the following two findings-first, the simulation game can be a useful means to train competencies for resilient transport operations from the perspective of the future planners and decision makers, as well as for soon-to-be professionals in container terminals. Second, the game may help participants to make choices that lead to resilient transport operations in container terminals.
\end{abstract}

Keywords Simulation gaming - Resilience - Intermodal transport operations · Container terminals

Shalini Kurapati

S.Kurapati@tudelft.nl

1 Delft University of Technology, Delft, The Netherlands 
Mathematics subject classification $91 \mathrm{C} 99 \cdot 68 \mathrm{U} 35 \cdot 90 \mathrm{~B} 06$

\section{Introduction}

"So, the first big thing that changed was the introduction of the container. When we think about technology that changed the world, we think about glamorous things like the Internet. But if you try to figure out what happened to world trade, there is a really strong case to be made that it was the container, which could be hauled off a ship and put onto a truck or a train and moved on"-Paul Krugman (Stern 2010).

The importance of intermodal freight transportation using containers does not need more emphasis than the statement of Krugman (Stern 2010, p. 7). Over $80 \%$ of the volume of global merchandize is carried by sea and handled by ports worldwide (UNCTAD 2013). Containers carry more than $70 \%$ of the value of this seaborne trade facilitated by a seamless transfer of goods with multiple modes of transportation (UNCTAD 2007). Therefore container transport is synonymous with intermodal transport (Muller 1999). Containers are handled in seaport terminals, which are crucial interfaces between landside and seaside transportation, and between various modes of transport. Seaports have been identified as critical infrastructures, which are essential elements that affect the economical and social well-being of any country (EC 2008; Mokhtari et al. 2012). Seaport operations are influenced by the complex and dynamic interactions among multiple stakeholders, modes, industries, operating systems, liability regimes, legal frameworks, etc. (OECD 2005). With an equivalent compounded annual growth rate of $10 \%$, the increasing volumes of containers exert pressure on seaports to handle them without compromising on efficiency of operations and turn-around times of ships (Kemme 2013). In addition to these stochastic factors, intermodal operations at seaport container terminals are managed by disparate groups of individuals and departments who are responsible for complex and time-sensitive technical operations at the terminals. This makes seaport container terminals vulnerable to both external and internal risks and disruptions (Longo 2012; O’Reilly et al. 2004).

\subsection{Disruption in seaports and ripple effects: the need for resilience}

Unplanned and unanticipated events that affect the normal flow of goods and operations in supply and transport networks are termed as disruptions (Svensson 2000). Unfortunately, disruptions have become common phenomena in port operations. The main categories of disruptions are port accidents, port equipment failures, dangerous goods mishandling, port congestion, inadequacy of labour skills, hinterland inaccessibility, breach of security, and labour strikes (Loh and Thai 2012). These disruptions not only affect the seaport operations, but also can have dire consequences on the operations and activities of the entire transportation and supply network, as well as on the economic and societal well-being of the surrounding environment (Yliskyla-Peuralahti et al. 2011). There are several 
Table 1 Effect of Finnish stevedore port disruption on some companies in key sectors (Yliskyla-Peuralahti et al. 2011)

\begin{tabular}{lll}
\hline Sector & Type of company & $\begin{array}{l}\text { Time period before production stopped } \\
\text { (lack of raw materials) after disruption } \\
\text { at port }\end{array}$ \\
\hline Energy & Oil & $2-3$ days \\
& Coal & 3 months \\
Food supply and exports & Grain imports/exports & Several months \\
& Meat and meat products & $2-3$ weeks \\
& Animal feed and malt & $2-3$ weeks \\
& Wholesaler of food & $2-3$ days \\
& Milk products & $2-3$ days \\
Electronics & Power and automation products & $2-3$ days \\
Healthcare supplies & Healthcare products & $2-8$ weeks \\
Forestry & Paper and pulp & 12 h to 2 days \\
Metal & Metal products & $2-3$ weeks to months \\
\hline
\end{tabular}

examples that support this argument. For instance, Table 1 indicates how the unplanned closure of ports in Finland affected the production of several Finnish industries in 2010.

The East Japan earthquake in 2011 heavily disrupted the operations of the northeastern Japanese seaports, which affected the activities of the warehouses and production facilities served by the port areas (Takahashi et al. 2011). Another famous example is that of the 2002 longshoreman union strike at US West Coast ports, which interrupted services to many US-based firms, with port operations and schedules not returning to normal until 6 months after the strike ended (Cavinato 2004). A large interoperability study conducted thereafter revealed that the losses for the regional and national economy were estimated to be $\$ 1.94$ billion for each day the port closure continued (Cohen 2002).

In addition to the economic benefits, seaports also provide societal services in the form of job creation. One in 24 jobs in southern California is directly associated with the Port of Los Angeles (Jung et al. 2009), while the Port of Rotterdam employs around 86,000 people, close to $14 \%$ of the total number of inhabitants of Rotterdam (Port of Rotterdam 2009).

\subsubsection{Resilience principles}

Given the undesirable ripple effects caused by disruptions in seaport operations in the whole transport and supply network, it can be deduced that the resilience of seaports is essential for the resilience and robustness of transport systems in a whole. Resilience in the context of seaports is consistent with supply chain literature, defined as the capability of a system or organization to bounce back to its normal functions in spite of disruptions (Sheffi 2005). Regardless of the operational domain, the resilience of a system or organization is defined by its ability to 'respond to the actual, monitor the critical, anticipate the potential, and learn from 


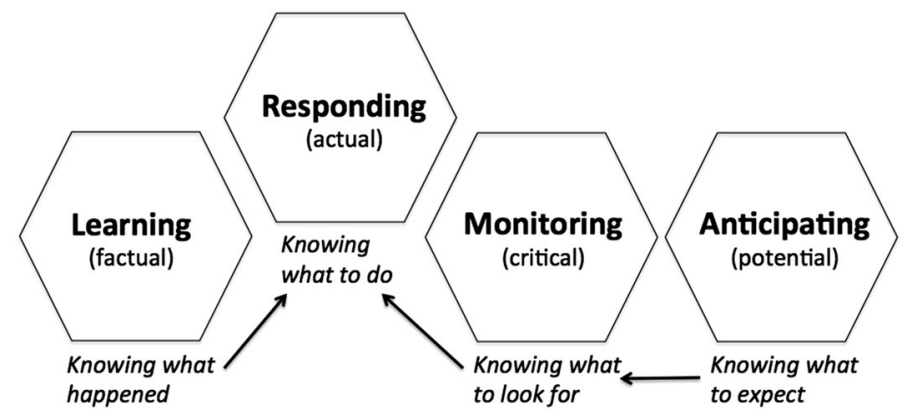

Fig. 1 Four cornerstones of resilience (Hollnagel 2011)

the factual' (Hollnagel 2011). These four cornerstones of operationalizing the principles of resilience are shown in Fig. 1.

However, applying these principles for resilient intermodal operations have several challenges, which are discussed in detail in the following section.

\subsection{Research problem: challenges in disruption management in seaport container terminals}

Although not all disruptions in seaports have such grave consequences as described in the previous section, they cause delays to other parties, as well as backlogs, queues, extra traffic around the port, and chaos in operating procedures, which in turn could lead to safety issues. Therefore, it is essential to improve the resilience of seaport operations to handle disruptions (Loh and Thai 2012). The quick detection and management of disruptions by sharing pertinent information to the right person or department at the right time, and having a shared awareness of the effects of disruptions improves the resilience of an organization or a system (Craighead et al. 2007).

Because containerized transportation plays such a big role in international trade (UNCTAD 2013), we will focus on container operations in seaports in this paper. Several planning and operational departments manage seaport container terminal operations. These departments take part in addressing complex disturbances as well. The common approach to solve complex problems is to decompose them into subproblems and solve them sequentially, in this case, e.g., on a department-bydepartment basis. This leads to undesirable results and sub-optimal solutions. The inter-dependencies between various planning and operational departments and the need for alignment and coordination of solution strategies have been largely overlooked (Meier and Schumann 2007). Though there has been quite some research on supply chain disruption management, there has been less focus on holistic and integrated disruption management of seaport container terminals (Loh and Thai 2012).

As a first step to address this gap, this research paper introduces simulation gaming as an approach towards increasing awareness of planners and decision makers in seaport operations regarding information sharing, inter-dependencies, 
coordination, and shared awareness during disruption management to improve the resilience of seaport container terminals. As the cost of errors is extremely high in real-life disruption situations, we chose simulation gaming as a safe alternative to train professionals and soon-to-be professionals where decision skills during disruptions can be enhanced without heavy cost implications (Dumblekar 2004).

The ensuing research question investigated in this paper is as follows:

How can simulation gaming facilitate decision-making for resilient intermodal transport operations in a safe training environment?

The following sections introduce the complex operations at seaport container terminals, the choice to use simulation gaming, the development and deployment of a multi-player game for disruption management in seaport container terminals, a discussion on the results, followed by the conclusions and some final comments.

\section{Intermodal operations at seaport container terminals}

Intermodal transport operations in ports are located at container terminals. Their layout can be decomposed into three parts—-seaside operations, storage operations and landside operations. On the seaside or quayside of the terminal, containers are either unloaded from or loaded onto massive sea vessels. On the landside, containers are loaded onto or unloaded from trucks, trains and barges. ${ }^{1}$ The storage area of the terminal is called the yard, where containers are stored in stacks, thus facilitating the decoupling of seaside and landside operations (Voss et al. 2004). There are special transport vehicles that move containers from the quayside to the yard and vice versa. These can be, e.g., trucks, straddle carriers, or automated guided vehicles (AGVs) in (semi) automated ports. Several types of cranes perform the loading, unloading and storage operations. Containers can belong to three categories-import, export or transhipment containers. Import containers are brought in by deep-sea vessels, stored in the terminal briefly, and need to be transported to the hinterland. Export containers follow the opposite path. Transhipment containers need to be transferred from one deep-sea vessel to another without having to leave the terminal premises. The various planning and operational aspects of the container terminal can be summarized in Fig. 2.

The movement of large volumes of goods asks for complex planning processes in the terminal. Operations' planning is therefore a key component of container terminal management. The four major divisions in the planning operations are as follows:

1. Berth planning calls for deciding the mooring slot and time slot for the ships at the quay (sea side) where they can be served with a planned number of quay cranes;

2. yard planning allocates the storage spots in the yard for import, export and transhipment containers;

\footnotetext{
${ }^{1}$ Barge handling is considered to be landside as well, because it serves the hinterland.
} 


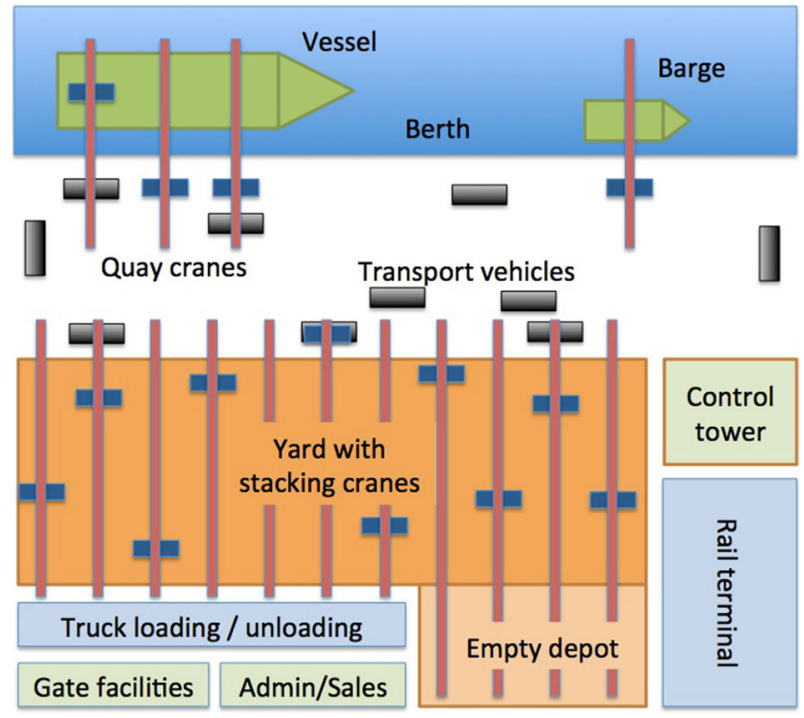

Fig. 2 Top-view of container terminal (adapted from Kemme 2013)

3. vessel planning requires to plan the order of unloading and loading of the containers from and onto the ship while guarding stability and safety of the vessel;

4. resource allocation reserves the required equipment and manpower for the above planning operations.

In addition to the planning departments, the two main roles that influence the operations of the container terminal are the control tower operator and sales department. The control tower of the terminal monitors the planning and operational activities of the terminal, and the sales division takes care of transactions with the clients.

All these roles are modelled in the simulation game presented in Sect. 3.2, with the exception of the berth planner, which is automated in the game play for the sake of playability.

\section{Simulation gaming: an approach to improve resilience in seaport terminal operations}

\subsection{An introduction to simulation games}

Simulation games are defined as 'a conscious endeavour to reproduce the central characteristics of a system in order to understand, experiment with and/or predict the behaviour of that system' (Duke 1980). It is a method in which human participants enact a specific role in a simulated environment (Duke and Geurts 
2004). Simulation games are used to train specific skills, transfer knowledge, or develop new strategies or policies. Such games are being used as a means to analyse and change complex systems in many ways. There is a wide variety of fields in which simulation games have been employed, both in research and practice, and for a broad range of purposes, like training, teaching, performing scientific research and experiments (Peters and Van de Westelaken 2011; Van Os 2012).

In our case, we focus on the use of simulation games as a training tool as well as a research instrument to observe the behaviour of the participants and help them assess different futures, and explore their decision processes. This implies that our simulation game is meant to improve communication between stakeholders, and to improve their (shared) awareness of the situation in seaport container terminals. Simulation games have the potential to provide a rich environment with many objects. They can represent complex systems from different perspectives (Bekebrede 2010), and can relate these systems to a certain narrative or to changing scenarios. Simulation games are experiential, experimental and rigorous tools that enable participants to gain new insights in a given situation, to develop a shared view of their learning and behaviour, and help them think and act innovatively in a safe and controlled environment (Dumblekar 2004). With the possibility of team and multi-player game modes, a set of players can play simultaneously, and a shared situational understanding of a given context can be developed within such a group of players. Having this potential, simulation games not only support learning and skill development, but also support individual and team awareness, understood as a prerequisite to decision-making (Faria et al. 2009; Mayer 2009; Egenfeldt-Nielsen 2007).

\subsection{Conceptual model for game design}

For the conceptualization and design of the simulation game, we follow the framework by Meijer (2009). According to this framework, a simulation game is always designed with an objective (for learning purposes) or based on a research question (research purposes). The game consists of roles, rules, objectives, constraints, load and situation, which are controlled by the game designer as shown in Fig. 3. A major part of the proposed framework by Meijer (2009) in its

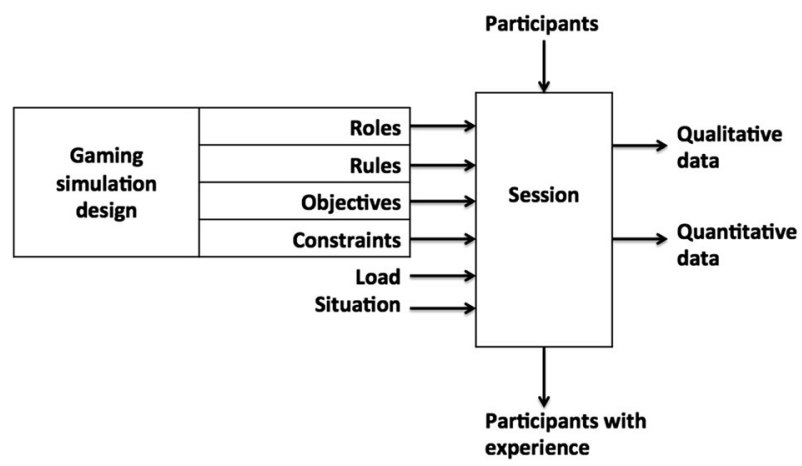

Fig. 3 Input and output elements of a simulation game session (Meijer 2009) 
current form (Fig. 3) is based on earlier research in the field of simulation gaming. The representation of a simulation game as an operational model of a real-life system to understand, experiment with and predict the behaviour of the actors/participants in the system is based on the work of Duke (1980) and Duke and Geurts (2004). The concept of roles, rules, objectives and constraints are based on Gibbs' (1974) definition of the structure of simulation games. The characteristics and use of simulation games to understand complex systems and situations are also well described by Klabbers (2006). The term 'load' is based on Wenzler's (2003) work on the transformational capacity of simulation games.

The roles in a simulation game are abstract interpretations of their real-world equivalents. Participants assume their allotted roles in the game, which can be different from their regular role. The roles determine their objectives in the game and the possibilities to take actions. The game facilitator who orchestrates the session also has a role, which is mainly pre-scripted (Meijer 2009).

The rules control the game play. They can be generic or specific to certain participants. They are used as abstractions to simulate real-world behaviour, and to steer the behaviour of the participants in the game play (Meijer 2009).

Objectives of the simulation game guide the participants towards the necessary actions they need to take to achieve success in the game play. Different roles could have different objectives, or an objective could be a collective effort of a set of roles. Objectives provide motivation and incentives for the participants to be involved in the game session. They can also be used to shape the behaviour of the participants, and are useful for the learning experience of the game (Meijer 2009).

Constraints limit the actions that the participants can take during a simulation game. An example of a constraint could be a time limit to make choices, or penalty points for a bad action (Meijer 2009).

Load of the simulation game allows the game to be played in different configurations, allowing flexibility and versatility in the use of the game. This could be modelled in terms of levels of the game with different difficulty. The game session can either run with a constant load or varying loads (Meijer 2009).

Situation is the environment in which the simulation game session is organized. The selection of participants, the location of game play and the purpose of the game session constitute the situation of the game session (Meijer 2009). Participants enter a game session with or without expectations and are expected to gain some learning experience by participating in the session. The game session itself produces both qualitative and quantitative data for further analyses to investigate the research objectives of the game session. The following section describes how resilience can be incorporated as a learning experience using simulation gaming.

\subsection{Resilience and simulation games}

Training participants for escalating situations in complex and dynamic situations can help them manage disruptions as they can evaluate their shortcomings and decisions in a safe manner (Bergström et al. 2011). As we know from our previous discussions that disruptions in intermodal transportation cause undesirable ripple effects that escalate unless sufficient mitigation actions are taken. However, 


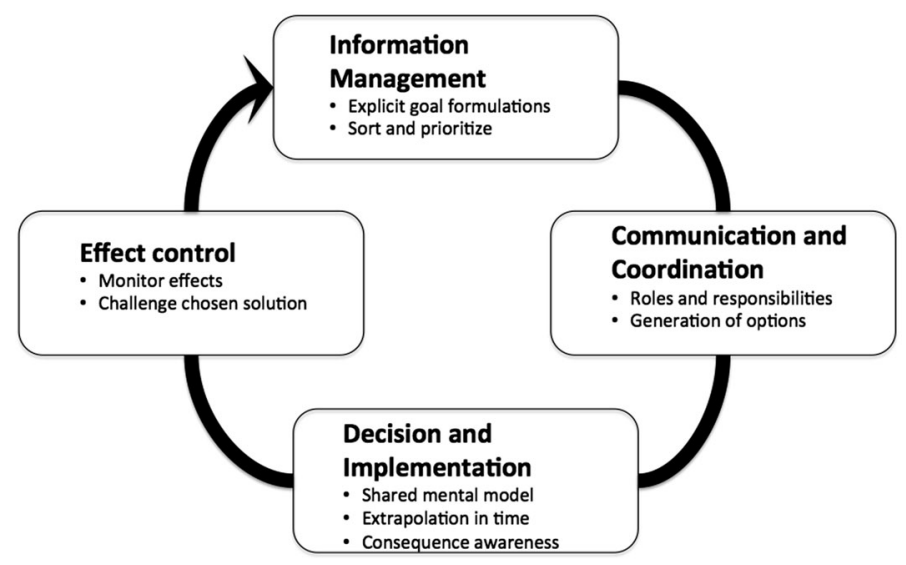

Fig. 4 Competencies for organizational resilience (Bergström et al. 2011)

mitigation is not a stand-alone process, and requires teamwork in such complex settings with multiple stakeholders. Several team competencies have been identified as prerequisites for securing organizational resilience, which are illustrated in Fig. 4 (Bergström et al. 2011).

Based on the above conceptual game design model and the resilience principles for organizational resilience, a tabletop game has been specifically designed to simulate disruption management for intermodal operations in seaport container terminals. The description of the game is provided in detail in the following section.

\subsection{The disruption management game for intermodal operations in seaports}

The disruption management game for intermodal transport operations in ports is a five-player tabletop board game, which will be henceforth referred to as the 'game'. The key motivation of the development and deployment of the game is twofold:

Firstly to explore the role of simulation gaming in training resilience competencies of stakeholders in organizations; Secondly to increase the awareness of the decision makers in the seaport container terminals about the importance of communication and information sharing, need for coordination, the role of interdependencies during disruption management to improve resilience of seaport container terminals in a safe and controlled environment.

Based on literature and brainstorming sessions with professionals in the container terminal business, the challenges in disruption management of container terminal operations have been translated into contextualized game play. The development of the game took over 8 months, as it was an iterative process with design, evaluation and validation cycles, with several prototypes being shelved. 


\subsubsection{Game description}

The game is set in a container terminal in a seaport as a crucial interface in intermodal transportation. It consists of five different roles, each responsible for specific planning and operational tasks in the container terminal. As the game unfolds, disruptions start occurring that drastically affect individual operations as well as the operation of the entire organization. The unfolding of the game is modelled using the concept of rounds. With each round, the event complexity increases and disruption situation escalates, unless some action by the players is taken. Five rounds make one level. At the end of each level, the disruption situation further escalates as a new disruption occurs. In each round, every player receives exclusive information, which he or she could choose to share with other players during the game play. For each round every player has two decision options (A or B) to take action on the escalating situation. The effects of disruption on the system have been modelled as the game scores or key performance indicators (KPIs). There are two scores-individual and organizational. Depending on whether a player chose decision option A or B, the individual score either increases or decreases. The organizational score increases or decreases based on the individual scores. An MS Excel-based scoring model has been designed to compute various individual and organizational scores for various decision options. In order to make the 'right' decision and 'win' the game, participants need to manage information, communicate and coordinate if necessary, monitor the effects of disruptions and take the necessary actions at the right time to mitigate the negative effects. Five rounds constitute one level. The game has three difficulty or complexity levels. In every successive level a new disruption unfolds in addition to the existing disruptions creating a more complex scenario for information exchange, coordination, effect control and decision-making.

The various disruption scenarios modelled in the game are based on literature as described in Sect. 1.1. The three scenarios with varying degrees of severity that unfold in each of the different levels are as follows:

1. Equipment failure-A crucial crane in the container terminal is dysfunctional. The cause is unknown and needs to be investigated. Equipment failures cause operational backlogs and queues.

2. Accident in the terminal-A worker has been injured in an accident, and all the operations of the terminal are shut down until the whole situation is assessed. Operations of the terminal are seriously affected by such a disruption, as a safe operating environment needs to be established again, operational efficiency has to be improved to account for backlogs, while not making customers wait too long.

3. Truckers' strike-This is the most severe of the disruption scenarios as it creates the most ripple effects in the transport network. Truckers are external stakeholders consolidated by a strong union. They announce an indefinite strike to improve their working conditions and wages. Trucks are crucial for hinterland transportation. A strike could mean that containers pile up in the yard and the terminal has to look for alternative ways to transport the containers. It is 
obvious that operational efficiency and customer satisfaction are affected, but safety is also affected because the high workload and stress, and adoption of alternative methods of transportation could create confusion and chaos in the terminal, which in turn affect the safety of the operating environment. The degree of severity implies event complexity. As each disruption unfolds, participants need to manage many more operations, and process more information from different sources.

The game is described in Table 2, using the terms of the input/output model from Meijer (2009).

Table 2 Input and output elements in the disruption management game

Input/output Description in the game

elements

Roles

Rules

Objectives

Constraints

Load

Situation

Participants

Qualitative data

Quantitative data
Vessel planner, yard planner, resource planner, control centre manager, sales (refer to Sect. 2)

At the start of the game, all the individual and organizational scores are set to a maximum score of ten points. The scores decline after every round, and can only be increased by mitigation actions of participants

Participants have information cards and action cards, the former used for communication, the latter for performing mitigation actions

Information can be exchanged using e-mail, phone, or a conference call. Limited tokens are given to each participant. These tokens need to be 'spent' to communicate. E-mail costs fewer tokens but has a lower chance of being read immediately. The chance is determined by a throw of a die

Mitigation cards vary for each round in every level. They contain two decision choices-A and B from which participants need to choose one mitigation card; examples of mitigation actions include "Cordon off the automated area until the repairs are done"; "Call the ambulance to attend for the injured"; "Organize alternative transport options for the containers", etc.

Based on the decision choices of the participants the scores after every round are computed by an MS Excel-based scoring model

To maintain the organizational score of the seaport terminal as close as possible to the maximum possible score (ten points)

To maintain the individual scores close as possible to the maximum possible score (ten points)

Information availability, time, resources to communicate

Different disruption situations, different levels of escalation of disruptions, varying channels and cost of communication and information sharing, different game boards at different levels to control the shared awareness of the participants

University classrooms; logistics, supply chain and transportation companies; professional and knowledge institutes

Academic researchers, students and professionals in the transportation, logistics and supply chain industry

Observations from the game session by the game facilitator, report of decisions after every round

Post-game survey answered by the participants. The individual and organizational scores per round and per level 


\subsubsection{Learning objectives}

The learning objectives of the game are founded on the key elements for resilience in transport operations in the game based on the team competencies for organizational resilience by Bergström et al. (2011) have been modelled.

Information management has been modelled such that players need to process the available information they are provided with, as well as the information received from other players in the course of the play. Players need to exchange information using information cards - the right information to the right player at the right time to make the optimal mitigation action choice. They need to be aware of their individual goals, the roles and responsibilities of other players, and situational understanding of the effects. They also have to prioritize information received and request necessary information to make the best mitigation actions.

Communication and coordination has been modelled in the game such that if the participants do not exchange information and align their activities, their mitigation actions could be redundant or cancel each other out without increasing the KPIs, and thereby hurt the resilience of the terminal operations. Several channels of communication are provided in the game such as e-mail and phone. These can be utilized by spending 'communication tokens' that represent time and resources spent for communication. Coordination mechanisms in the game include aligning plans using conference calls, de-briefing sessions and teaming up.

Effect control, decision and implementation have been modelled as the effects of the mitigation actions that are translated into individual and organizational scores. After each round the effect of mitigation actions of the players is reflected on the scores. Individual mitigation actions of players not only affect individual scores but could also affect, either positively or negatively, the scores of other players. All the individual scores contribute to the organizational score of the container terminal. Therefore the effect control is modelled in terms of score, which enables players to reflect upon their choices to prepare for the next round. The decision and implementation competencies have been modelled as the various choices participants have to make to mitigate the disruption.

The next section discusses the application of this simulation game with students and professionals.

\subsection{Design of the game session}

A simulation game is not a stand-alone instrument. In order to deliver the full potential of the game, it is usually presented to the participants in the form of a game session. For the disruption management game, the game session adopted is described in Fig. 5.

For each of the test sessions, participants were gathered around a table in a spacious room. The room was prepared in advance for the game play, by prearranging the required game objects. Depending on the size of the group one or more game facilitators orchestrated the game play. The game facilitator was given a game manual that describes their role and the method of orchestration. 


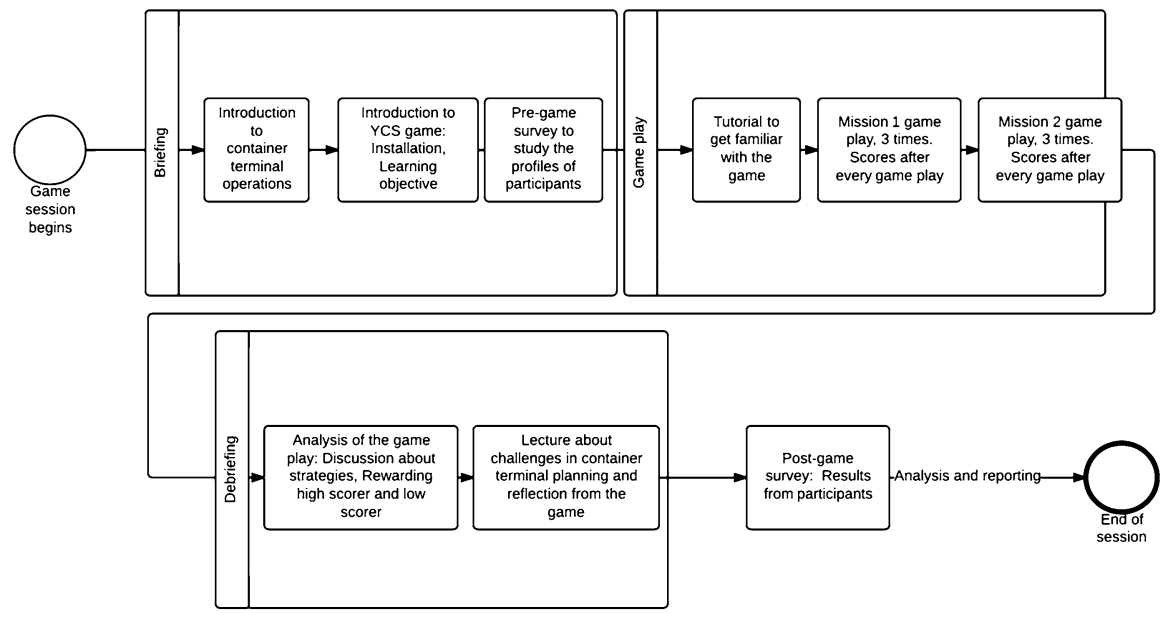

Fig. 5 Game session designed for the disruption management game

Every game session begins with a briefing, usually lasting 20-25 min. The various intermodal operations, terminal processes, roles in the container terminal, and the equipment used are described in the introduction. The disruption management game is then introduced along with the role of the game facilitator. The objectives, rules, setup and scoring are briefly introduced.

The game play begins after the briefing session. Each level of the game play lasts about $1 \mathrm{~h}$, which means each round has a duration of about $12 \mathrm{~min}$. After every round, the game facilitator provides individual and organizational scores to the players, along with an explanation of the effect of the decisions on KPIs. At the end of five rounds, which is the end of a level, an overview of the situation at the terminal is presented to all the participants and their decisions are briefly re-visited. This game play repeats in all three levels. Before starting each of the levels, the facilitator introduces the change of rules. The game play is observed thoroughly by the game facilitator, and after every round the decisions and scores are recorded.

The game session concludes with a de-briefing session, where the game facilitator explains the principles of disruption management, the challenges faced by practitioners, the relationship of the game elements to the said challenges, the progress of the game play, a review of the scores and the reasons for obtaining these scores, potential alternative strategies, a comparison between scores of different play groups and the reasons for the differences, etc. The purpose of this part of the game session is mainly to provide a learning experience to the participants.

After the de-briefing session the game facilitator encourages the participants to provide feedback about the game and their own learning experience. Finally, an online survey is sent to the participants, to get detailed feedback about their learning experience and further suggestions.

The data gathered from the game, the videos and the survey were analysed qualitatively after each game session to gather insights into disruption management 
for resilient intermodal port operations. Several game sessions were conducted based on the above design. The setup of these test sessions is described in the next subsection.

\subsection{Setup of game sessions}

The disruption management game for port operations was conducted in an exploratory setting with several groups of participants in several different locations. The setup of the sessions analysed in this paper are listed in Table 3.

The evaluation of the game session is based on Meijer's (2009) simulation game input/output model described in Sect. 3.2. The two kinds of data generated in the game sessions are qualitatively, by observational data and quantitatively, by survey data. In each session, the game facilitator observes the game play and makes notes regarding the behaviour of the participants. At the end of each round of the game play, the game leader records the decisions of the participants and the corresponding individual and overall scores in a scorecard. The game facilitator also records the feedback from the participants during the de-briefing session.

The survey data are gathered via a post-game survey to record their learning experience. The aim of the survey is to gather feedback from the participants regarding their experiences, as well as to compare the data from observations with the experience of the participants.

Given the availability of a large group, the survey was conducted in game sessions conducted at a university in the United States among a group of 80 participants in the form of an online questionnaire. The composition of the participants is as follows: $33 \%$ bachelor students, $44 \%$ master students, and $23 \%$ pursuing their graduate studies in the field of supply chain management.

Based on the analyses of the observational and survey data of the game sessions in Table 3, the following section describes the results obtained.

Table 3 Setup of the game sessions

\begin{tabular}{|c|c|c|c|c|}
\hline $\begin{array}{l}\text { Number } \\
\text { of } \\
\text { sessions }\end{array}$ & $\begin{array}{l}\text { Number of } \\
\text { participants }\end{array}$ & Participants' profile & Location & $\begin{array}{l}\text { Type of data } \\
\text { from the } \\
\text { session }\end{array}$ \\
\hline 3 & 10 & Academic researchers and students & $\begin{array}{l}\text { Technical university in } \\
\text { the Netherlands }\end{array}$ & $\begin{array}{l}\text { Observational } \\
\text { data }\end{array}$ \\
\hline 1 & 15 & $\begin{array}{l}\text { Professionals from transport and } \\
\text { supply chain industry }\end{array}$ & $\begin{array}{l}\text { Professional and } \\
\text { knowledge institute } \\
\text { for logistics and } \\
\text { supply chain }\end{array}$ & $\begin{array}{l}\text { Observational } \\
\text { data }\end{array}$ \\
\hline 5 & 80 & $\begin{array}{l}\text { Undergraduate, master and } \\
\text { graduate students majoring in } \\
\text { supply chain, logistics and } \\
\text { transportation }\end{array}$ & $\begin{array}{l}\text { University in the } \\
\text { United States }\end{array}$ & $\begin{array}{l}\text { Observational } \\
\text { and survey } \\
\text { data }\end{array}$ \\
\hline
\end{tabular}




\section{Results and discussion}

The results and discussion is based on the research question posed in the beginning of the paper as well as the main objectives of the simulation game discussed in the game description chapter. As stated before, the results and discussion focus on how the simulation game can help train competencies for organizational resilienceinformation management, communication and coordination, effect control and decision and implementation. The second objective is to understand how increased awareness of these competencies can help participants to be more prepared to deal with disruptions in real life. The results are analysed based on the said objectives. The results are reported in two ways: firstly, qualitatively by observation of the game play by the game master; secondly, quantitatively based on a survey posed to the participants of the game sessions to assess their learning effects pertaining to the objectives of the simulation game. The following section discusses the results.

\subsection{Results from observation}

The observation of the game play of the various game sessions yielded valuable insights into the behaviour of the participants during disruption management in the game.

\subsubsection{Overview of the game observations}

The overall observation of the game play was in line with the objectives of the simulation game. The participants' approach to information sharing, communication, and balancing trade-offs during disruption management was observed. One of the most promising results that emerged from the analyses was the clear difference in the behavioural patterns of players at different game levels. In level 1 of the game play, all players had limited awareness and understanding of the disruption scenario, the potential effects of their mitigation actions, and their role and objective in the game, and they made individualistic decisions. In the early rounds, there was a lot of confusion, distress among players while having to communicate and take mitigation actions in a black-box-like environment, given the time pressure. Largely, information was being requested from/sent to the wrong providers/recipients. In level 2, players had a higher awareness of the situation. They made good use of the available communication channels, as they understood who needed their information and who possessed the information they needed. The flow of redundant information reduced compared to level 1. Players tried to attune their plans, considering the decisions of others. In level 3, players had more discussions and negotiations. Players came up with innovative ways of teaming up to jointly mitigate the situation. Sometimes, players compromised their individual KPIs to boost the overall KPIs. Well-informed and rational decisions were best made in level 3 [see also Kurapati et al. (2013)]. 
More detailed observations regarding the behaviour of the participants for the main elements required for resilient transport operations are explained in the following subsections.

\subsubsection{Information management and communication}

Participants were able to share information via different communication channels with varying costs and probabilities. Each of the participants was given a limited number of tokens for communication. E-mail communication costs fewer tokens but is less effective than a phone call, which costs more. In the beginning, participants were unable to prioritize the urgency of the information to be sent, and would send it via e-mail which sometimes got lost in spam or was not read by the recipient. The lost information could affect the mitigation choice of the intended recipient. There were instances where the information was returned to the original sender after several rounds of communication between participants. Some participants received a lot of information, while others received nothing. As the time grew near to take mitigation actions, participants stopped communicating and started making choices by intuition. As participants became more aware of the roles and objectives of others during the game, the communication patterns improved and relevant information was shared at the right time with the right participants, directly affecting the mitigation actions. This improved the resilience of the terminal, as was indicated by the KPIs.

\subsubsection{Coordination}

In general, as the time pressure mounted, participants preferred to take individualistic decisions and were less keen on aligning their plans. This could be attributed to several reasons. Participants were unable to understand the need to align their mitigation actions, and if they did realize the need, they had excessive or inadequate information to do so.

\subsubsection{Effect control, decision and implementation}

Participants received feedback about their decision and the effect on individual and organizational score.

During the game play, participants initially focused on their individual scores. With each successive round, the escalation of the disruption negatively affected organizational scores. After observing these effects in a few rounds of game play, some participants sacrificed their individual scores to compensate for the organizational score of the container terminal, whereas some other participants were more strategic and increased their individual gains.

\subsubsection{Remarks}

The professionals who played the game (row 2 in Table 3) got acquainted with the game quicker than students, which may be because they understand the operations 
of the container terminals better than the students. However, when the disruption situation escalates their performance was not much different from that of the students. It is also observed in practice that professionals in the supply chain and transportation field are not prepared enough to deal with disruptions to secure organizational resilience (Bragdon 2008).

This difference leads us to infer the following:

1. The fact that professionals understood the functioning of the game very easily compared to the students serves as face validity for the level of 'realism' in the board game.

2. The observation that there was no substantial difference between the performances of students and professionals demonstrates that professionals could very well make the same mistakes as novices under stress when the disruption escalate.

3. Simulation gaming should not be limited to training of students, who are soonto-be professionals, but also of the current professionals for disruption management to ensure organizational resilience.

As only ten professionals played the sessions, this is merely an observation rather than a conclusion. Also, professionals needed less briefing time regarding the terminal operations and challenges. Therefore the main difference in the sessions was the timeframe. Sessions with students took 30 min longer than those of the professionals due to more questions during the game sessions as well as a longer briefing procedure.

In addition to the observations, the following section describes the results gathered from the post-game survey.

\subsection{Results from survey: learning experience of participants}

Along with evaluating the overall experience, the post-game survey focused on understanding the learning experiences of the student participants after the game session, regarding the concepts of communication and information sharing, coordination and interdependencies during disruption managements for resilient intermodal seaport container terminal operations. The results obtained from the survey are described in the following subsections.

\subsubsection{Overall learning experience}

To assess the overall learning experience, the student participants were asked the following question,

As future supply chain professionals, how helpful do you think are the learning principles of the disruption management game are to prepare you to handle real-world disruptions? (Rate on the following options: Not helpful, Slightly helpful, Helpful, Very helpful, Extremely helpful). 
About $37 \%$ of the participants felt that the learning experience from the game would be helpful, $16 \%$ responded that it would be very helpful, and $38 \%$ felt that it would be moderately helpful, $9 \%$ answered slightly helpful to better prepare them to handle real-world disruptions. Not even one participant responded that it would be not helpful.

In addition to the rating scale as a response to the above question, there was a comment section to gather a more descriptive experience of the participants. The responses were largely positive. The synopsized comments are as follows.

Most of the responses ( $75 \%$ ) began with 'I really enjoyed the experience of the game session'. The remarks of participants can be summarized as follows:

- It is a very interesting, interactive and practical simulation.

- It is a very good exercise to understand the importance of disruption management in transportation and supply chains.

- The game shows that it is difficult to pre-determine a perfect or optimal solution to manage disruptions.

- The game could have been more beneficial to the participants if they had more experience in the port industry.

- On the downside, the game is a bit complex and [it] took some time to understand the objective and its learning principles.

The responses regarding the resilience competencies apart from the overall learning experiences are described in the following subsections.

\subsubsection{Information management and communication}

As mentioned in the introductory chapter, relevant information sharing and communication are essential for resilient operations during disruptions. Therefore the student participants were asked questions on these elements.

Regarding information sharing participants were asked the following question:

How relevant was the information that you received from other players for your decision-making for disruption management? (Rate on the following options-Not relevant, Slightly relevant, Relevant, Very relevant, Extremely relevant).

In response to the above question, $20 \%$ of the participants felt that it was very relevant, while $57 \%$ felt that it was relevant, $16 \%$ felt that it was only slightly relevant, whereas $7 \%$ of the participant did not think it was relevant at all.

In addition to the above rating scale, an open-ended question was asked regarding the opinions of the participants on communication and information sharing after playing the disruption management game.

Most of the participants ( $80 \%$ ) felt that communication and information sharing are extremely important for disruption management of intermodal operations in seaport container terminal. Some of the descriptive answers of the participants are given below: 
- Communicating the right information at the right time is very important.

- Communication has to be done judiciously as time and resources are not unlimited during a disruption scenario.

- Integrating the different pieces of information is key to make good decisions.

- Communication is very important because it can affect crucial decisions of other participants during disruption management for resilient operations.

\subsubsection{Coordination}

Participants were asked an open-ended question regarding their ideas on coordination after playing the disruption management game, and the responses in a brief form are as follows:

- Coordination is essential for effective disruption management.

- It is very difficult to coordinate a good solution strategy during a disruption scenario.

- All participants need to coordinate amongst themselves to mitigate disruptions through effective communication.

\subsubsection{Effect control, decision and implementation}

Regarding the effect control participants were asked the following question,

How helpful was the feedback given after each round (the announcement of scores and system status) to make decisions in the subsequent rounds?

In response to the above question, $45 \%$ of the participants replied that it was very helpful, $27 \%$ reported that it was somewhat helpful and $28 \%$ of the participants did not find it helpful for taking decisions on mitigation action.

In the survey, learning effect regarding decision and implementation has not been explicitly measured, but the overall decision and implementation regarding mitigations actions is the consequence of good information management, communication, coordination and effect control (Bergström et al. 2011). However, in a concluding open question of the survey, that prompted the participants to add their comments on other aspects of the game, the following responses were related to the decision and implementation.

- Decision-making during disruption management is more complex and interdependent than one thinks.

- It is important to adopt an inter-dependent view during disruption management rather than a top down approach: a big picture perspective is essential.

- The focus on individual score hinders the 'common good' (organizational score).

- Participants need to consider organizational scores before making mitigation choices. 
Based on the discussed results both from the observation as well as from the survey, conclusions have been drawn. The limitations of the research will also be presented, leading to future research.

\section{Conclusions and future work}

Resilience of intermodal transport operations is essential for the robustness of the entire transport transportation system. The disruption game discussed in this paper provides a means to observe the management of disruptions by participants in a safe and controlled environment.

Referring back to the research question posed in the beginning of the paperHow can simulation gaming help improve the resilience of intermodal transport operations at seaport container terminals, the observations and survey results support the following two initial conclusions. Firstly, simulation gaming can be a good training exercise for soon-to-be professionals in the field of transportation and supply chain to train their competencies to ensure organizational resilience in seaport terminals. Based on the observational data of the professionals we believe that this conclusion could be extended to professionals as well. Secondly, the awareness created by training these resilience competencies may improve the preparedness of professionals and soon-to-be professionals in the field of transportation and supply chain to ensure organizational resilience in real life.

With respect to the first conclusion, we are aware of the fact that a simulation game is always just a model of reality. In order to design a playable activity, certain aspects of reality have to be left out, or brought to a higher abstraction level. So far the results of the sessions discussed above show that the players value the realism of the game as sufficient in relation to the "learning" objective. Therefore future work will focus on the research related the fidelity of the game, and conduct further expert validation to assess the relationship between game and reality.

Regarding the second conclusion, we acknowledge that the game has been employed only with a few professionals and mainly with students in the field of supply chain and transportation. Additionally, the learning effect measured by a survey after the game session is subjective, as it measures only the self-perception of the participants regarding the game. The survey is administered immediately after the game, so the learning effect measured is short-term and its lasting effects cannot be determined. However, long-term research is required in understanding the applications of simulated learning in real-life situations. The limitation of the research also extends to the restricted scalability of the board game to conduct largescale and long-term experimental sessions. It is also a challenging task to prove what the pure influence of simulation gaming is if participants perform well at securing organizations resilience. Nonetheless, future work will include more sessions of the game with professionals. This could provide deeper insights into the effects of using a simulation game on training competencies for resilience in reallife operations. Also a mobile version of the game is being developed for distributed 
situations, enabling more simultaneous sessions and data collection in a more realistic setting.

Acknowledgments The research described in this paper is part of the SALOMO project, which is financially supported by DINALOG, the Dutch Institute for Advanced Logistics. The authors would like to thank Dr. Gwendolyn Kolfschoten for helping developing the simulation game. Many thanks also to Prof. Thomas Corsi, and Dr. Stephanie Eckerd and their students at the R.H. Smith School of Business, University of Maryland, and students at Delft University of Technology for their participation in the test sessions.

Open Access This article is distributed under the terms of the Creative Commons Attribution 4.0 International License (http://creativecommons.org/licenses/by/4.0/), which permits unrestricted use, distribution, and reproduction in any medium, provided you give appropriate credit to the original author(s) and the source, provide a link to the Creative Commons license, and indicate if changes were made.

\section{References}

Bekebrede G (2010) Experiencing complexity: a gaming approach for understanding infrastructure systems. Ph.D. thesis. Delft University of Technology, The Netherlands

Bergström J, Dahlström N, Dekker S, Petersen K (2011) Training Organisational Resilience in Escalating Situations. In: Hollnagel E, McDonald N, Woods D, Wrethall J (eds) Resilience engineering in practice: a guidebook. Ashgate, Surrey, pp 45-56

Bragdon C (2008) Transportation security. Butterworth-Heinemann, Oxford

Cavinato JL (2004) Supply chain logistics risks: from the back room to the board room. Int J Phys Distrib Logist Manag 34(5):383-387

Cohen SS (2002) Economic impact of a West Coast dock shutdown. University of California at Berkeley, Berkeley. http://brie.berkeley.edu/publications/ships\%202002\%20final.pdf. Accessed 7 July 2015

Craighead CW, Blackhurst J, Rungtusanatham MJ, Handfield RB (2007) The severity of supply chain disruptions : design characteristics and mitigation capabilities. Decis Sci 38(1):131-156

Duke RD (1980) A paradigm for game design. Simul Gam 11(3):364-377. http://sag.sagepub.com/ content/11/3/364.full.pdf

Duke RD, Geurts J (2004) Policy games for strategic management. Rozenberg, Amsterdam

Dumblekar V (2004) Management simulations: tests of effectiveness. Online posting on simulation and gaming: an interdisciplinary journal of theory, practice and research. Website. http://www.unice.fr/ sg/resources/articles/dumblekar_2004_management.htm. Accessed 7 July 2015

EC (2008) Council Directive 2008/114/EC, 75-82. http://eur-lex.europa.eu/LexUriServ/LexUriServ. do?uri=OJ:L:2008:345:0075:0082:EN:PDF. Accessed 7 July 2015

Egenfeldt-Nielsen S (2007) Educational potential of computer games. Continuum, London/New York

Faria A, Hutchinson J, Wellington WJ, Gold S (2009) Developments in business gaming. Simul Gam 40(4):464-487

Gibbs GI (1974) Handbook of games and simulation exercises. Sage Publications Inc, Beverly Hills

Hollnagel E (2011) Prologue: the scope of resilience engineering. In: Hollnagel E, Pariès J, Woods D, Wreathall J (eds) Resilience engineering in practice: a guidebook. Ashgate, Surrey, pp xxix-xxxix

Jung J, Santos JR, Haimes YY (2009) International trade inoperability input-output model (IT-IIM): theory and application. Risk Anal 29(1):137-154

Kemme N (2013) Design and operation of automated container storage systems. Springer, Heidelberg. http://dl.acm.org/citation.cfm?id=2414765

Klabbers JH (2006) A framework for artifact assessment and theory testing. Simul Gam 37(2):155-173

Kurapati S, Kolfschoten G, Verbraeck A, Corsi TM, Brazier F (2013) Exploring shared situational awareness in supply chain disruptions. In: Comes T, Fiedrich F, Fortier S, Geldermann J, Müller T (eds) 10th international conference on information systems for crisis response and management. KIT, Baden-Baden, pp 151-155 
Loh HS, Thai VV (2012) The role of ports in supply chain disruption management. In: Proceedings of the international forum on shipping, ports and airports. The Hong Kong Polytechnic University, Hong Kong, pp 325-337

Longo F (2012) Supply chain security: an integrated framework for container terminal facilities. Int J Simul Process Model 7(3):159-167

Mayer I (2009) The gaming of policy and the politics of gaming: a review. Simul Gam 40(6):825-862

Meier L, Schumann R (2007) Coordination of interdependent planning systems, a case study. In: Marc RK, Herzog O, Rodiger K-H, Ronthaler M (eds) Informatik 2007. Gesellschaft fur Informatik e.V, Bremen, pp 389-396

Meijer S (2009) The organisation of transactions: studying supply networks using gaming simulation. Ph.D. thesis. Wageningen University, The Netherlands

Mokhtari K, Ren J, Roberts C, Wang J (2012) Decision support framework for risk management on sea ports and terminals using fuzzy set theory and evidential reasoning approach. Expert Syst Appl 39(5):5087-5103

Muller G (1999) Intermodal freight transportation. Eno Foundation for Transportation, Washington, DC

O’Reilly GP, Houck DJ, Eunyoung K, Morawski TB, Picklesimer DD, Uzunalioglu H (2004). Infrastructure simulations of disaster scenarios. In: Networks 2004-11th international telecommunications network strategy and planning symposium. IEEE, Vienna, pp 205-210. http:// ieeexplore.ieee.org/xpls/abs_all.jsp?arnumber $=1341842$

OECD (2005) Container transport security across modes. Organisation for Economic Co-operation and Development, Paris

Peters V, Van de Westelaken M (2011) Spelsimulaties-een Beknopte Inleiding in het Ontwerpproces (Simulation games - a brief introduction to the design process). Samenspraakadvies, Nijmegen

Port of Rotterdam (2009) Rotterdam World-class Port. Port of Rotterdam Authority, Rotterdam

Sheffi Y (2005) The resilient enterprise: overcoming vulnerability for competitive advantage. MIT Press, Cambridge

Stern R (2010) Comparative advantage, economic growth, the gains from trade and globalization, and computational trade modeling: Festschrift papers in honor of Alan V. Deardorff. University of Michigan, Ann Arbor. http://141.213.232.243/handle/2027.42/66468

Svensson G (2000) A conceptual framework for the analysis of vulnerability in supply chains. Int J Phys Distrib Logist Manag 30(9):731-749

Takahashi S, Kuriyama Y, Tomita T (2011) Urgent survey for 2011 Great East Japan Earthquake and Tsunami disaster in ports and coasts-part I (Tsunami). Port and Airport Research Institute, Kanagawa

UNCTAD (2007) Review of Maritime Transport 2007. United Nations Conference on Trade and Development, New York http://medcontent.metapress.com/index/A65RM03P4874243N.pdf

UNCTAD (2013) Review of Maritime Transport 2013. United Nations Conference on Trade and Development, New York. http://unctad.org/en/publicationslibrary/rmt2013_en.pdf

Van Os M (2012). Using gaming as a data collection tool to design rules for agents in agent-based models. M.Sc. thesis. Delft University of Technology, The Netherlands

Voss S, Stahlbock R, Steenken D (2004) Container terminal operation and operations research-a classification and literature review. OR Spectr 26(1):3-49

Wenzler I (2003) The portfolio of 12 simulations within one company's transformational change initiative. In: Arai K (ed) Social contributions and responsibilities of simulation and gaming. ISAGA, Chiba

Yliskyla-Peuralahti J, Spies M, Tapaninen U (2011) Transport vulnerabilities and critical industries: experiences from a Finnish stevedore strike. Int J Risk Assess Manag 15(2/3):222-240. http:// inderscience.metapress.com/index/U1X2507P74L28117.pdf 